\title{
Effect of Ag addition on the mechanical and thermoelectric performances of annealed $\mathrm{Bi}_{2} \mathrm{Sr}_{2} \mathrm{Co}_{1.8} \mathrm{O}_{x}$ textured ceramics
}

\author{
A. Sotelo, ${ }^{1}$ M. A. Torres, ${ }^{2}$ G. Constantinescu, ${ }^{1}$ Sh. Rasekh, ${ }^{1}$ J. C. Diez, ${ }^{1}$ M. A. \\ Madre $^{1, *}$ \\ ${ }^{1}$ ICMA (CSIC-Universidad de Zaragoza), Dpto. de Ciencia de Materiales, \\ C/María de Luna 3, 50018-Zaragoza (Spain). \\ ${ }^{2}$ Universidad de Zaragoza, Dpto. de Ingeniería de Diseño y Fabricación, \\ C/María de Luna 3, 50018-Zaragoza (Spain).
}

\begin{abstract}
$\mathrm{Bi}_{2} \mathrm{Sr}_{2} \mathrm{Co}_{1.8} \mathrm{O}_{\mathrm{x}} / \mathrm{Ag}$ composites with small amounts of $\mathrm{Ag}$ have been synthesized by a sol-gel via nitrates reaction and directionally grown from the melt. Some of the obtained samples were annealed in order to obtain the thermoelectric phase as the major one. As-grown and annealed samples were microstructurally characterized to determine the phases distribution and alignment. Moreover, thermoelectric and mechanical characteristics of annealed samples were determined by the four-probe technique and by three point flexural strength tests, respectively. Scanning electron microscopy revealed that Ag particles appear dispersed among well oriented ceramic grains with large size, providing a plastic flow region which increases the flexural strength for the optimally $\mathrm{Ag}$ added samples (1wt.\%). The composites electrical resistivity is lower than that of pure $\mathrm{Bi}_{2} \mathrm{Sr}_{2} \mathrm{Co}_{1.8} \mathrm{O}_{\mathrm{x}}$ while $\mathrm{Ag}$ addition does not significantly affect thermopower values. The resistivity reduction leads to power factor
\end{abstract}


improvements of $\sim 50 \%$, compared with pure samples, for $\mathrm{Ag}$ additions of 1wt.\%Ag.

Keywords: Grain growth; Microstructure-final; Mechanical properties; Electrical properties; Thermopower.

* Corresponding author. Tel.: +34 976762617; fax: +34 976761957

e-mail address: amadre@unizar.es 


\section{Introduction}

Thermoelectric (TE) materials can transform a temperature difference to electrical power directly due to the well-known Seebeck effect. The conversion efficiency of such materials is quantified by the dimensionless figure of merit ZT, $\mathrm{TS}^{2} / \rho \kappa$ (in which $\mathrm{S}^{2} / \rho$ is also called power factor, $\mathrm{PF}$ ), where $S$ is the Seebeck coefficient (or thermopower), $\rho$ the electrical resistivity, $k$ the thermal conductivity, and $\mathrm{T}$ is the absolute temperature. ${ }^{1}$ This important characteristic has focused attention on this type of materials in order to be applied in practical applications as waste heat recovery devices ${ }^{2}$ or solar thermoelectric generators. ${ }^{3}$ Furthermore, they can also be used as calefaction/refrigeration devices. ${ }^{4}$ Nowadays, these commercial applications are based on the use of alloys and/or intermetallic thermoelectric materials, such as $\mathrm{Bi}_{2} \mathrm{Te}_{3}$ or $\mathrm{CoSb}_{3}$, with high thermoelectric performances. On the other hand, these materials posses some drawbacks, as they can be degraded at high temperatures under air and/or releasing toxic or heavy elements. These problems lead to the limitation of their working temperature which reduces their effective performances. This temperature limitation was overwhelmed in $1997^{5}$ by the discovery of attractive thermoelectric properties in ceramics such as $\mathrm{Na}_{2} \mathrm{Co}_{2} \mathrm{O}_{4}$. From the discovery of this thermoelectric oxide, much work has been performed on these materials leading to the discovery of new compositions, such as $\mathrm{Ca}_{2} \mathrm{Co}_{2} \mathrm{O}_{5}{ }^{6}$ or $\mathrm{Bi}_{2} \mathrm{Sr}_{2} \mathrm{Co}_{1.8} \mathrm{O}_{x},{ }^{7}$ with high thermoelectric properties. The crystal structure of these families can be described as an alternate stacking of two different layers, a common conductive $\mathrm{Cdl}_{2}$-type $\mathrm{CoO}_{2}$ layer with a twodimensional triangular lattice and a block layer composed, in turn, of insulating rock-salt-type (RS) layers. Both sublattices (RS block and $\mathrm{Cdl}_{2}$-type layer) 
possess common a- and $c$-axis lattice parameters and $\beta$ angles but different $b$ axis length, causing a misfit along the b-direction. ${ }^{8}$ As a consequence of their crystal structure, layered cobaltites are characterized by a high anisotropy which leads to the formation of plate-like grains during the crystallization process. This feature can be exploited in the development of commercial applications for these ceramics, with improved electrical properties, when an adequate grain orientation is produced using texturing techniques. Such grains alignment would allow attaining macroscopic properties comparable to those obtained on single crystals. Numerous methods have been reported to be efficient to obtain a good grain alignment, such as spark plasma sintering, ${ }^{9,10}$ sinter-forging, ${ }^{11}$ templated grain growth $(\mathrm{TGG})^{12}$ or the laser floating zone (LFZ) melting technique. ${ }^{13}$ These methods can be roughly divided into two different groups: those producing grain alignment in solid state or with a small liquid phase proportion (as the spark plasma sintering) and those which produce grain orientation via crystallization from the melt (as the LFZ technique).

On the other hand, the poor mechanical characteristics of this kind of materials, due to their ceramic nature, may impose limitations for their practical applications. Some attempts to improve the mechanical properties of other layered ceramics have been performed by $\mathrm{Ag}$ addition on bulk sintered or textured materials, ${ }^{14,15}$ while no studies have been published, to our knowledge, for the mechanical improvement of bulk or textured $\mathrm{Bi}_{2} \mathrm{Sr}_{2} \mathrm{Co}_{1.8} \mathrm{O}_{\mathrm{x}}$ thermoelectric ceramics.

The aim of this work is to study the effect produced by the Ag addition on $\mathrm{Bi}_{2} \mathrm{Sr}_{2} \mathrm{Co}_{1.8} \mathrm{O}_{\mathrm{x}}$ thermoelectric ceramics when they are textured using the LFZ technique which completely melts the sample. Moreover, the modification of 
$\mathrm{Bi}_{2} \mathrm{Sr}_{2} \mathrm{Co}_{1.8} \mathrm{O}_{x} / \mathrm{Ag}$ composites properties is considered after annealing at $800^{\circ} \mathrm{C}$ for $24 \mathrm{~h}$. The changes produced on the annealed samples microstructure are related with their thermoelectric and mechanical properties.

\section{Experimental}

Previous results of Ag addition on textured layered ceramics have shown that the amount of Ag which produces an improvement on the ceramic mechanical properties, depends on the bulk material density. ${ }^{14,15}$ Usually, the textured ceramics produced using the LFZ technique have a very high density ( $\geq 95 \%)$. As a consequence, small wt.\% Ag amounts can lead to important improvements of their mechanical performances.

According to these previous results obtained on ceramics with similar structure, $\mathrm{Bi}_{2} \mathrm{Sr}_{2} \mathrm{Co}_{1.8} \mathrm{O}_{x} / \mathrm{x}$ wt.\%Ag ceramic composites with small Ag additions $(\mathrm{x}=0,1$, and 3) have been prepared from commercial $\mathrm{Bi}\left(\mathrm{NO}_{3}\right)_{3} \cdot 5 \mathrm{H}_{2} \mathrm{O}(\geq 98 \%$, Aldrich), $\mathrm{CaCO}_{3}\left(98.5 \%\right.$, Panreac), $\mathrm{Co}\left(\mathrm{NO}_{3}\right)_{2} \cdot 6 \mathrm{H}_{2} \mathrm{O}(98 \%$, Panreac), and metallic $\mathrm{Ag}$ (99.9\%, Aldrich) powders using a sol-gel method via nitrates. ${ }^{16}$ The powders were weighed in the adequate proportions and suspended in distilled water. Concentrated $\mathrm{HNO}_{3}$ (analysis grade, Panreac) was added dropwise into the suspension until it turned into a clear pink solution. Citric acid (99.5\%, Panreac), and ethylene glycol (99 \%, Panreac), were added to this solution in the adequate proportions.

Evaporation of the solvent was performed slowly in order to decompose the nitric acid excess, which allows the polymerization reaction between ethylene glycol and citric acid, forming a pink gel. ${ }^{17}$ The dried product was then decomposed (slow self combustion) by heating at $350^{\circ} \mathrm{C}$ for $1 \mathrm{~h}$. The resulting 
powder was thermally treated twice, at 750 and $800^{\circ} \mathrm{C}$ for $12 \mathrm{~h}$ each one, with an intermediate milling, to assure complete carbonate decomposition. This process is of the main importance as it is necessary to avoid carbonates decomposition inside the melt produced on the LFZ process which would lead to the crystallization front destabilization.

The calcined powder was then isostatically pressed at $200 \mathrm{MPa}$ in form of cylindrical bars ( $2 \mathrm{~mm}$ diameter) which were used as feed in a LFZ device equipped with a continuous power Nd:YAG solid-state laser $(\lambda=1.06 \mu \mathrm{m})$, as described elsewhere. ${ }^{18}$ The texturing processes were performed downwards with a growth speed of $30 \mathrm{~mm} / \mathrm{h}$ and a feed rotation of $15 \mathrm{rpm}$ to ensure compositional homogeneity of the molten zone. The use of this relatively high crystallization rate implies that the growth process does not occur in equilibrium. For this reason, the obtained textured cylinders are formed by several phases which can react to form the thermoelectric $\mathrm{Bi}_{2} \mathrm{Sr}_{2} \mathrm{Co}_{1.8} \mathrm{O}_{x}$ phase when the samples are properly annealed. The textured bars (around $2 \mathrm{~mm}$ diameter) were then cut to obtain samples of adequate dimensions for the electrical and mechanical characterizations (about $15 \mathrm{~mm}$ length). Some of the samples were kept for microstructural characterization (used as reference) while the others were annealed at $800^{\circ} \mathrm{C}$ during $48 \mathrm{~h}$ with a final furnace cooling.

Powder X-ray diffraction (XRD) patterns were systematically recorded by using a Rigaku EXAFS device, working with $\mathrm{Cu} \mathrm{K} \alpha$ radiation and $2 \theta$ ranging between 10 and 60 degrees, in order to identify the different phases in the as-grown and annealed thermoelectric textured materials.

Microstructures were observed by using a JEOL 6000 scanning electron microscope (SEM) equipped with an energy-dispersive spectroscopy (EDS) 
device used for phase identification. Micrographs of transversal and longitudinal polished sections were recorded to observe grain orientation and to analyze the composition and distribution of the different phases. The approximate amounts of each phase were determined on several SEM micrographs using Digital Micrograph software.

Mechanical characterization was performed measuring the flexural strength by the three-point bending test in an Instron 5565 machine with $10 \mathrm{~mm}$ loading span fixture and a punch displacement speed of $30 \mu \mathrm{m} / \mathrm{min}$.

Electrical resistivity and thermopower were simultaneously determined by the standard dc four-probe technique in a LSR-3 measurement system (Linseis $\mathrm{GmbH})$. They were measured in the steady state mode at temperatures ranging from 50 to $650^{\circ} \mathrm{C}$ under $\mathrm{He}$ atmosphere. With the electrical resistivity and thermopower data, PF has been calculated in order to determine the samples performances.

\section{Results and discussion}

As-grown samples

As indicated previously, the $\mathrm{Bi}-\mathrm{Sr}-\mathrm{Co}-\mathrm{O}$ ceramic system melts incongruently. As a consequence, after the growth process the samples are composed of several phases. This behaviour is illustrated in Fig. 1, where SEM micrographs of representative transversal polished sections of the $\mathrm{Bi}_{2} \mathrm{Sr}_{2} \mathrm{Co}_{1.8} \mathrm{O}_{\mathrm{x}} / \mathrm{x}$ wt. $\% \mathrm{Ag}$ sample are displayed. In Fig. 1a, where the pure $\mathrm{Bi}_{2} \mathrm{Sr}_{2} \mathrm{Co}_{1.8} \mathrm{O}_{\mathrm{x}}$ textured ceramic is presented, five different contrasts can be easily observed, as reported previously, ${ }^{19}$ each one associated to a different phase by EDX. The phases and their amount in the different Ag-added samples are nearly the same, 
independently of $\mathrm{Ag}$ content, indicating that the melt is chemically similar and that Ag produces minor effects on the solidification process. The approximate proportion of each phase in all the samples has been determined analyzing several SEM images for each composition. The identified phases, together with their mean proportion are: 1. $\mathrm{CoO}\left(\sim 0.5\right.$ vol. \%, black contrast); $2 . \mathrm{Sr}_{2} \mathrm{Co}_{1.8} \mathrm{O}_{\mathrm{a}}(\sim$ 1.0 vol. \%, dark grey one); $3 . \mathrm{Bi}_{2} \mathrm{Sr}_{2} \mathrm{Co}_{1.8} \mathrm{O}_{x}\left(\sim 48\right.$ vol. \%, grey); 4. $\mathrm{Bi}_{2} \mathrm{Sr}_{2} \mathrm{CoO}_{\delta}(\sim$ 40 vol. \%, light grey one); and 5. Co-free phase ( 10 vol. $\%$, white one). On the other hand, Ag particles can be observed (indicated by arrows) in Fig. 1b, where higher magnification micrograph of the transversal polished section of the $\mathrm{Bi}_{2} \mathrm{Sr}_{2} \mathrm{Co}_{1.8} \mathrm{O}_{\mathrm{x}} / 1 \mathrm{wt} \% \mathrm{Ag}$ sample is shown. The mean size of these $\mathrm{Ag}$ particles is about $3 \mu \mathrm{m}$ for the $1 \mathrm{wt} . \%$ Ag samples while for the $3 \mathrm{wt} . \%$ it is increased until around $6 \mu \mathrm{m}$.

Other interesting feature can be observed in Fig. 2, where a representative longitudinal polished section of the $\mathrm{Bi}_{2} \mathrm{Sr}_{2} \mathrm{Co}_{1.8} \mathrm{O}_{x} / 3$ wt. $\% \mathrm{Ag}$ sample is presented. From this micrograph, it is clear that grains posses a good preferential orientation quasi-parallel to the growth axis. Moreover, their microstructure can be approximately described as alternated $\mathrm{Bi}_{2} \mathrm{Sr}_{2} \mathrm{Co}_{1.8} \mathrm{O}_{x} / \mathrm{Bi}_{2} \mathrm{Sr}_{2} \mathrm{CoO}_{\delta}$ layers, with intercalated Co-free phase, while the other three phases $\left(\mathrm{CoO}, \mathrm{Sr}_{2} \mathrm{Co}_{1.8} \mathrm{O}_{a}\right.$, and $\left.\mathrm{Ag}\right)$ are found as very small inclusions between the main phases.

From the above microstructural observations, it is clear that the samples can follow an annealing process in order to promote the formation of a higher amount of thermoelectric $\mathrm{Bi}_{2} \mathrm{Sr}_{2} \mathrm{Co}_{1.8} \mathrm{O}_{x}$ phase from the reaction of secondary phases. This thermal treatment has been performed at $800^{\circ} \mathrm{C}$ during $48 \mathrm{~h}$ with furnace cooling to room temperature. 


\section{Annealed samples}

From the above discussed features found in the as-grown samples, it has been found to be adequate to subject them to a thermal treatment in order to promote the thermoelectric $\mathrm{Bi}_{2} \mathrm{Sr}_{2} \mathrm{Co}_{1.8} \mathrm{O}_{x}$ phase formation from the non-thermoelectric secondary phases. This process has been performed at $800^{\circ} \mathrm{C}$, under air, during $48 \mathrm{~h}$ with slow furnace cooling to room temperature.

Powder XRD patterns for the different $\mathrm{Bi}_{2} \mathrm{Sr}_{2} \mathrm{Co}_{1.8} \mathrm{O}_{x} / \mathrm{x}$ wt.\% Ag composite samples after annealing are displayed in Fig. 3. From these data, it is clear that all the samples are composed by the thermoelectric $\mathrm{Bi}_{2} \mathrm{Sr}_{2} \mathrm{Co}_{1.8} \mathrm{O}_{x}$ phase as the major one. The highest peaks belong to the misfit cobaltite phase and are in agreement with previously reported data. ${ }^{20}$ The \# indicates the Si (111) diffraction peak, used as reference, and * shows the (111) peak of $\mathrm{Ag}$, and + corresponds to the Co-free secondary phase. ${ }^{21}$ These results clearly indicate that nearly pure phase can be obtained in a relatively short annealing time, at the adequate temperature, from the as-grown materials.

Figure 4 displays SEM micrographs performed on longitudinal polished sections of the $\mathrm{Bi}_{2} \mathrm{Sr}_{2} \mathrm{Co}_{1.8} \mathrm{O}_{\mathrm{x}} / \mathrm{x}$ wt. \% Ag samples after annealing. At first sight, it is clear that grain limits are not as clear as they were on the as-grown samples. More careful observation shows that for all the samples, $\mathrm{Bi}_{2} \mathrm{Sr}_{2} \mathrm{CoO}_{\delta}$ phase (light grey contrast, \#4 in Fig. 1) proportion decreases drastically, together with a slight reduction of $\mathrm{CoO}$ and $\mathrm{Sr}_{2} \mathrm{Co}_{1.8} \mathrm{O}_{a}$ ones (black and dark grey contrasts, indicated by \#1 and 2 in Fig. 1, respectively). This reduction is produced by the $\mathrm{Bi}_{2} \mathrm{Sr}_{2} \mathrm{Co}_{1.8} \mathrm{O}_{x}$ phase formation from the $\mathrm{Bi}_{2} \mathrm{Sr}_{2} \mathrm{CoO}_{\delta}$, CoO, and $\mathrm{Sr}_{2} \mathrm{Co}_{1.8} \mathrm{O}_{a}$ phases. As a consequence, $\mathrm{CoO}$ and $\mathrm{Sr}_{2} \mathrm{Co}_{1.8} \mathrm{O}_{a}$ phases are only found in very 
small amounts (about 1 vol. \% as a whole) and remain practically constant for all the samples. The main difference between them is found on the $\mathrm{Bi}_{2} \mathrm{Sr}_{2} \mathrm{CoO}_{\delta}$ (12 $\%$ for the pure sample, $8 \%$ for the $1 \mathrm{wt} . \% \mathrm{Ag}$, and $4 \%$ for the $3 \mathrm{wt} . \% \mathrm{Ag}$ one) and Co-free phase (about $9 \%$ in the pure sample and $6 \%$ for the $\mathrm{Ag}$ added ones) proportions. These small differences in the secondary phases content confirm that $\mathrm{Ag}$ addition modifies the phase equilibrium diagram and, as a consequence, the samples microstructure.

In order to determine $\mathrm{Ag}$ influence on the $\mathrm{Bi}_{2} \mathrm{Sr}_{2} \mathrm{Co}_{1.8} \mathrm{O}_{x} / \mathrm{x}$ wt. $\% \mathrm{Ag}$ composites mechanical behaviour, flexural strength tests were made on annealed specimens, using at least six samples for each composition. In Fig. 5 the flexural strength values are represented, together with their standard error, as a function of $\mathrm{Ag}$ content. At first sight, it is clear that $\mathrm{Ag}$ addition reduces the data dispersion in all cases, compared with the ones without Ag. Moreover, 1 wt.\% Ag addition improves mechanical properties in an important manner (around 40 $\%$ ) due to the small size and good distribution of Ag particles all over the ceramic matrix. This effect is produced by the Ag particles found between thermoelectric grains, providing a plastic-flow region which reduces crack propagation, as reported for similar layered materials. ${ }^{14,15}$ The decrease of flexural strength for higher Ag contents can be associated to the bigger size of some of these Ag particles which can act as stress amplifiers. Anyway, these 3 wt.\% Ag added samples show similar mean flexural stress values, compared with the pure ones, but a significant reduction on the data dispersion. 
Electrical resistivity measurements as a function of temperature have been performed on the annealed samples and displayed in Fig. 6. As it can be clearly seen, all the samples show very similar metallic-like behaviour in all the measured temperature range. Moreover, $1 \mathrm{wt} . \% \mathrm{Ag}$ samples posses the lowest resistivity values $(\sim 11 \mathrm{~m} \Omega . \mathrm{cm}$ at room temperature), compared with the pure $\mathrm{Bi}_{2} \mathrm{Sr}_{2} \mathrm{Co}_{1.8} \mathrm{O}_{\mathrm{x}}(\sim 18 \mathrm{~m} \Omega . \mathrm{cm}$ at room temperature) which is consistent with the reduction of the secondary phases content already mentioned in the microstructure discussion (see Fig. 4) and the higher grain alignment. On the other hand, higher Ag content increases slightly the measured resistivity values, probably due to the decrease on the grain alignment (see Fig. 4). The lowest resistivity value, obtained for the $1 \mathrm{wt} . \%$ Ag samples is close to that obtained for the best $\mathrm{Bi}_{2} \mathrm{Sr}_{2} \mathrm{Co}_{2} \mathrm{O}_{y}$ single crystals reported in the literature $(\sim 8 \mathrm{~m} \Omega . \mathrm{cm}$ at room temperature), ${ }^{22}$ indicating that metallic $\mathrm{Ag}$, with the adequate grain size, can effectively act as electrical bridges between thermoelectric grains, improving the electrical conductivity of these polycrystalline samples. Fig. 7 shows the variation of the Seebeck coefficient with the temperature, as a function of Ag content. It can be clearly seen that the sign of the thermopower is positive for the entire measured temperature range, which confirms a conduction mechanism predominantly governed by holes. The values of the thermopower increase with temperature, with the same behaviour for all the samples. This is a clear indication that these small amounts of Ag do not affect thermopower values. At room temperature, the $S$ values for all the samples are about $130 \mu \mathrm{V} / \mathrm{K}$ which are slightly higher than those reported in the literature $\left(\sim 120 \mu \mathrm{V} / \mathrm{K}\right.$ at $\left.275^{\circ} \mathrm{C}\right) .{ }^{12}$ Following the Koshibae's expression ${ }^{23}$ which relates $\mathrm{S}$ to the fraction of $\mathrm{Co}^{+4}$ over the total amount of cobalt, a relationship of about 
0.55 is obtained for all the samples. This value confirms that oxygen vacancies are approximately the same for all the samples, independently of the $\mathrm{Ag}$ content.

With the electrical resistivity and Seebeck factor values, PF variation with temperature has been calculated and represented in Fig. 8 as a function of $\mathrm{Ag}$ content. When considering PF values at room temperature, it can be clearly seen that $\mathrm{Ag}$ addition produces an important increase, from $0.10 \mathrm{~mW} / \mathrm{K}^{2} . \mathrm{m}$ for the pure compound to about $0.14 \mathrm{~mW} / \mathrm{K}^{2} . \mathrm{m}$ for the $3 \mathrm{wt} . \% \mathrm{Ag}$ samples, and $0.15 \mathrm{~mW} / \mathrm{K}^{2} . \mathrm{m}$ for the $1 \mathrm{wt} . \% \mathrm{Ag}$ samples. The maximum value at $650^{\circ} \mathrm{C}(0.27$ $\mathrm{mW} / \mathrm{K}^{2} . \mathrm{m}$ ) obtained for samples with $1 \mathrm{wt} . \% \mathrm{Ag}$ is higher than those measured on the ab plane (the conducting one) of textured materials at the same temperature (about $0.14 \mathrm{~mW} / \mathrm{K}^{2} . \mathrm{m}$ ). ${ }^{12}$ This important raise in PF (around $100 \%$ ) makes this kind of materials good candidates to explore the possibility to be applied in practical devices.

\section{Conclusions}

This work demonstrates that bulk $\mathrm{Bi}_{2} \mathrm{Sr}_{2} \mathrm{Co}_{1.8} \mathrm{O}_{x} / \mathrm{Ag}$ thermoelectric composites can be directionally grown by the laser floating zone method (LFZ). This process leads to a multilayer cobaltite with compositional differences between layers, mainly in Co content. After annealing, samples are composed mainly by the thermoelectric phase with small Ag inclusions which increase their size when the Ag content is raised. It has been found a significant increase (around $40 \%$ ) of flexural strength for samples with $1 \mathrm{wt} . \%$ Ag together with lower data dispersion, when compared with the pure samples. 
The optimal Ag addition has been determined using the values of the power factor at $50{ }^{\circ} \mathrm{C}$, which is maximum for the $1 \mathrm{wt} . \% \mathrm{Ag}$ added samples with values around $0.15 \mathrm{~mW} / \mathrm{K}^{2} \cdot \mathrm{m}$ (about $50 \%$ higher than the obtained for the Ag-free ones) and about $0.27 \mathrm{~mW} / \mathrm{K}^{2} \cdot \mathrm{m}$ at $650^{\circ} \mathrm{C}$, around two times higher than the best textured materials, measured in the ab plane, at the same temperature. These high PF values are obtained from the decrease on the electrical resistivity which reaches similar values to those obtained in single crystals. All these results make the $\mathrm{Bi}_{2} \mathrm{Sr}_{2} \mathrm{Co}_{1.8} \mathrm{O}_{\mathrm{x}} / 1 \mathrm{wt}$. $\% \mathrm{Ag}$ thermoelectric composite a promising material for practical power generation applications.

\section{Acknowledgements}

The authors wish to thank the Gobierno de Aragón (Research Groups T12 and T87), the Spanish Ministry for Science and Innovation-FEDER (Project MAT2008-00429), and the Universidad de Zaragoza (Project UZ2011-TEC-03) for financial support. The technical contributions of L. C. Estepa, J. A. Gómez and C. Gallego are also acknowledged. Sh. Rasekh acknowledges a JAEPreDoc2010 grant from CSIC. 


\section{References}

1. Rowe DM. In: Rowe DM, editor. Thermoelectrics handbook: macro to nano. 1st ed. Boca Raton, FL: CRC Press; 2006. p. 1-3-7.

2. Mahan G, Sales B, Sharp J. Thermoelectric materials: New approaches to an old problem. Phys Today 1997; 50:42-7.

3. Naito H, Kohsaka Y, Cooke D, Arashi H. Development of a solar receiver for a high-efficicency thermionic/thermoelectric conversion system. Solar Energy 1996;58:191-5.

4. Kim CM, Hwang YJ, Ryu YH. Air conditioner for individual cooling/heating. US Patent US6393842. May, 2002.

5. Terasaki I, Sasago Y, Uchinokura K. Large thermoelectric power in $\mathrm{NaCo}_{2} \mathrm{O}_{4}$ single crystals. Phys Rev B 1997;56:12685-7.

6. Funahashi R, Matsubara I, Ikuta H, Takeuchi T, Mizutani U, Sodeoka S. An oxide single crystal with high thermoelectric performance in air. Jpn J Appl Phys 2000;39: L1127-9.

7. Funahashi R, Matsubara I, Sodeoka S. Thermoelectric properties of $\mathrm{Bi}_{2} \mathrm{Sr}_{2} \mathrm{Co}_{2} \mathrm{O}_{x}$ polycrystalline materials. Appl Phys Lett 2000;76:2385-7.

8. Maignan A, Hébert S, Hervieu M, Michel C, Pelloquin D, Khomskii D. Magnetoresistance and magnetothermopower properties of $\mathrm{Bi} / \mathrm{Ca} / \mathrm{Co} / \mathrm{O}$ and $\mathrm{Bi}(\mathrm{Pb}) / \mathrm{Ca} / \mathrm{Co} / \mathrm{O}$ misfit layer cobaltites. J Phys: Condens Matter 2003;15:271123.

9. Zhang $\mathrm{Y}$, Zhang J, Lu Q. Synthesis of highly textured $\mathrm{Ca}_{3} \mathrm{Co}_{4} \mathrm{O}_{9}$ ceramics by spark plasma sintering. Ceram Int 2007;33:1305-8. 
10. Noudem JG, Kenfaui D, Chateigner D, Gomina M. Granular and lamellar thermoelectric oxides consolidated by spark plasma sintering. $J$ Electronic Mater 2011;40:1100-6.

11. Prevel M, Perez O, Noudem JG. Bulk textured $\mathrm{Ca}_{2.5}(\mathrm{RE})_{0.5} \mathrm{Co}_{4} \mathrm{O}_{9}(\mathrm{RE}: \mathrm{Pr}$, $\mathrm{Nd}, \mathrm{Eu}, \mathrm{Dy}$ and $\mathrm{Yb}$ ) thermoelectric oxides by sinter-forging. Solid State Sci 2007;9:231-5.

12. Itahara $\mathrm{H}$, Xia $\mathrm{C}$, Sugiyama J, Tani T. Fabrication of textured thermoelectric layered cobaltites with various rock salt-type layers by using beta-Co(OH $)_{2}$ platelets as reactive templates. J Mater Chem 2004;14:61-6.

13. Sotelo A, Guilmeau E, Madre MA, Marinel S, Lemonnier S, Diez JC. $\mathrm{Bi}_{2} \mathrm{Ca}_{2} \mathrm{Co}_{1.7} \mathrm{O}_{x}$ thermoelectric ceramics textured by laser floating zone method. Bol Soc Esp Ceram V 2008;47:225-8.

14. Joo J, Singh JP, Warzynski T, Grow A, Poeppel RB. Role of silver addition on mechanical and superconducting properties of High-Tc superconductors. Appl Supercond 1994;2:401-10.

15. Sotelo A, Mora M, Madre MA, Diez JC, Angurel LA, de la Fuente GF. Ag distribution in thick Bi-2212 floating zone textured rods. J Eur Ceram Soc 2005;25:2947-50.

16. Sotelo A, Rasekh Sh, Madre MA, Guilmeau E, Marinel S, Diez JC. Solutionbased synthesis routes to thermoelectric $\mathrm{Bi}_{2} \mathrm{Ca}_{2} \mathrm{Co}_{1.7} \mathrm{O}_{\mathrm{x}}$. J Eur Ceram Soc 2011;31:1763-9.

17. Gaoke Z, Ying L, Xia Y, Yanping W, Shixi O, Hangxing L. Comparison of synthesis methods, crystal structure and characterization of strontium cobaltite powders. Mater Chem Phys 2006;99:88-95. 
18. Diez JC, Angurel LA, Miao H, Fernandez JM, de la Fuente GF. Processing of textured BSCCO superconductors by laser-induced directional solidification. Supercond Sci Technol 1998;11:101-6.

19. Diez JC, Rasekh Sh, Constantinescu G, Madre MA, Torres MA, Sotelo A. Effect of annealing on the thermoelectric properties of directionally grown $\mathrm{Bi}_{2} \mathrm{Sr}_{2} \mathrm{Co}_{1.8} \mathrm{O}_{x}$ ceramics. Ceram Int 2012. DOI 10.1016/j.ceramint.2012.03.052 20. Xu GJ, Funahashi R, Shikano M, Matsubara I, Zhou YQ. Thermoelectric properties of $\mathrm{Bi}_{2.2-x} \mathrm{~Pb}_{x} \mathrm{Sr}_{2} \mathrm{Co}_{2} \mathrm{O}_{y}$ system. J Appl Phys 2002;91:4344-7.

21. Mercurio D, Champarnaud-Mesjard JC, Frit B, Conflant P, Boivin JC, Vogt T. Thermal evolution of the crystal-structure of the rhombohedral $\mathrm{Bi}_{0.75} \mathrm{Sr}_{0.25} \mathrm{O}_{1.375}$ phase - A single-crystal neutron-diffraction study. J Solid State Chem 1994;112:1-8.

22. Fujii T, Terasaki I, Watanabe T, Matsuda A. In-plane anisotropy on the transport properties in the modulated $\mathrm{Bi}_{2} \mathrm{O}_{2}$-based conductors $\mathrm{Bi}-2212$ and $\mathrm{Bi}$ Sr-Co-O. Physica C 2002;378-381:182-6.

23. Koshibae W, Tsutsui K, Maekawa S. Thermopower in cobalt oxides. Phys Rev B 2000;62:6869-72. 


\section{Figure captions}

Figure 1. SEM micrographs of representative transversal polished sections of the $\mathrm{Bi}_{2} \mathrm{Sr}_{2} \mathrm{Co}_{1.8} \mathrm{O}_{x}(\mathrm{a})$. The different identified phases are numbered as: 1) $\mathrm{CoO}$;

2) $\mathrm{Sr}_{2} \mathrm{Co}_{1.8} \mathrm{O}_{a}$; 3) $\mathrm{Bi}_{2} \mathrm{Sr}_{2} \mathrm{Co}_{1.8} \mathrm{O}_{x}$; 4) $\mathrm{Bi}_{2} \mathrm{Sr}_{2} \mathrm{CoO}_{8}$; and 5) Co-free phase. (b)

$\mathrm{Bi}_{2} \mathrm{Sr}_{2} \mathrm{Co}_{1.8} \mathrm{O}_{\mathrm{x}} / 1$ wt.\% Ag composite. Ag particles are indicated by arrows.

Figure 2. SEM micrograph of a representative longitudinal polished section of the $\mathrm{Bi}_{2} \mathrm{Sr}_{2} \mathrm{Co}_{1.8} \mathrm{O}_{x} / 3$ wt.\% Ag composite. The different contrasts correspond to the same phases described in Fig. 1.

Figure 3. Powder X-ray diffraction patterns obtained for the $\mathrm{Bi}_{2} \mathrm{Sr}_{2} \mathrm{Co}_{1.8} \mathrm{O}_{x} / \mathrm{x}$ wt.\% Ag composite samples; (a) 0; (b) 1; and (c) 3 wt.\% Ag. Co-free phase peak is indicated by $\mathrm{a}+$, the \# shows the Si (111) diffraction peak, used as reference, and * identify the (111) peak of Ag.

Figure 4. SEM micrographs of longitudinal polished sections of the annealed $\mathrm{Bi}_{2} \mathrm{Sr}_{2} \mathrm{Co}_{1.8} \mathrm{O}_{x} / \mathrm{x}$ wt.\% Ag composites, (a) 0; (b) 1; and (c) 3 wt.\% Ag. Grey contrast corresponds to the thermoelectric phase, white to the Co-free one, and light grey to the Co-poor one.

Figure 5. $\mathrm{Bi}_{2} \mathrm{Sr}_{2} \mathrm{Co}_{1.8} \mathrm{O}_{x} / \mathrm{x}$ wt.\% Ag annealed composites mechanical performances, together with their standard errors (three point flexure strength), as function of Ag content. 
Figure 6. Temperature dependence of the electrical resistivity as a function of Ag content in $\mathrm{Bi}_{2} \mathrm{Sr}_{2} \mathrm{Co}_{1.8} \mathrm{O}_{x} / x$ wt.\% Ag composite samples, $(\bigcirc)$ 0; $(\diamond)$ 1; and (घ) 3 wt. \% Ag.

Figure 7. Temperature dependence of the Seebeck coefficient as a function of Ag content in $\mathrm{Bi}_{2} \mathrm{Sr}_{2} \mathrm{Co}_{1.8} \mathrm{O}_{x} / x$ wt.\% Ag composite samples, $(\bigcirc) 0$; $(\diamond)$ 1; and (-) 3 wt.\% Ag.

Figure 8. Temperature dependence of the Power Factor as a function of $\mathrm{Ag}$

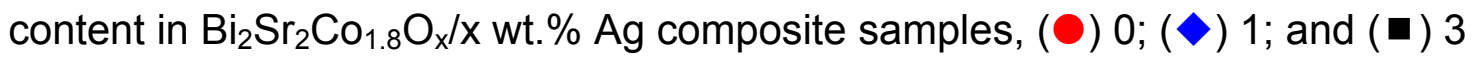
wt.\% Ag. 
Figure 1
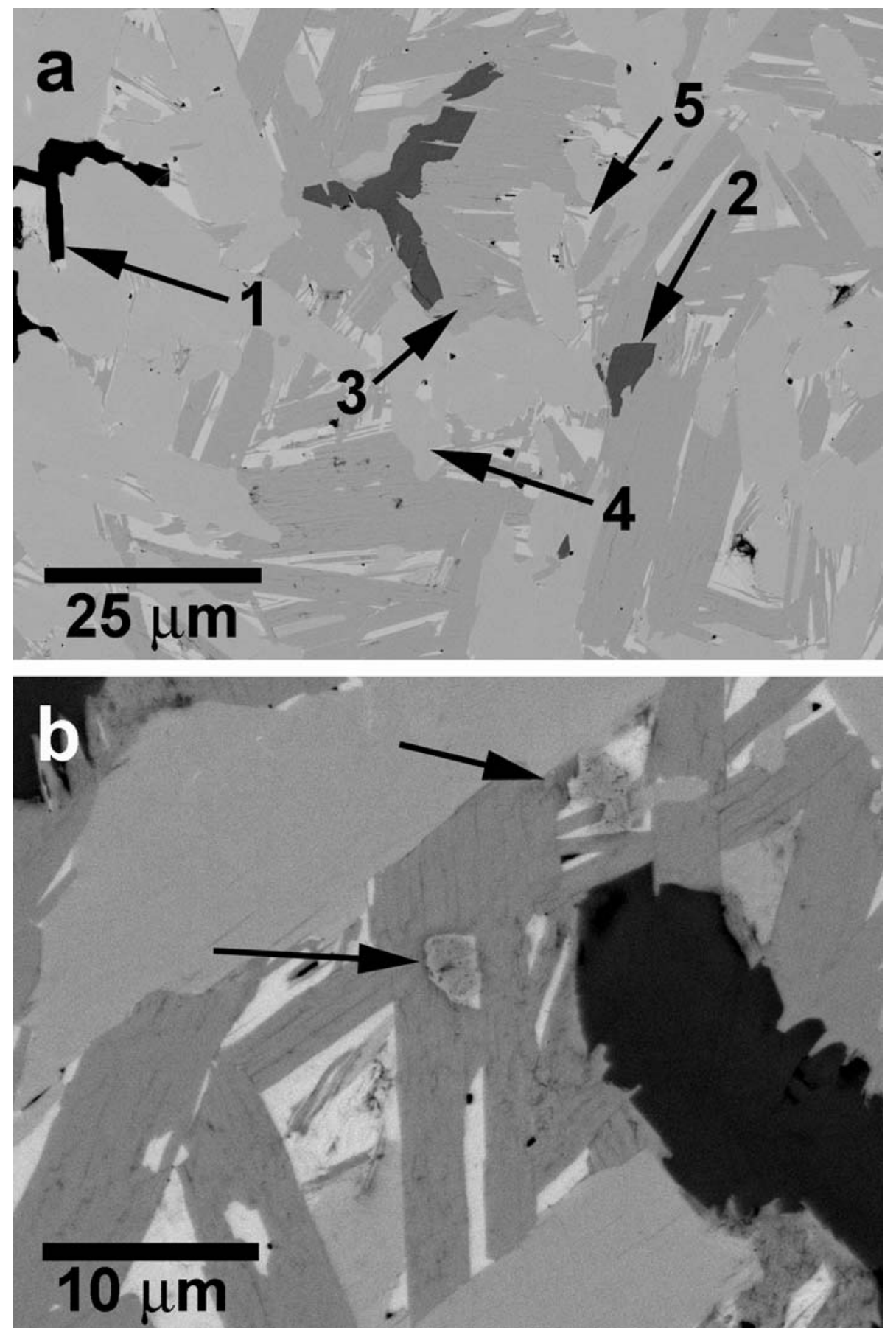
Figure 2

\section{Growth direction}

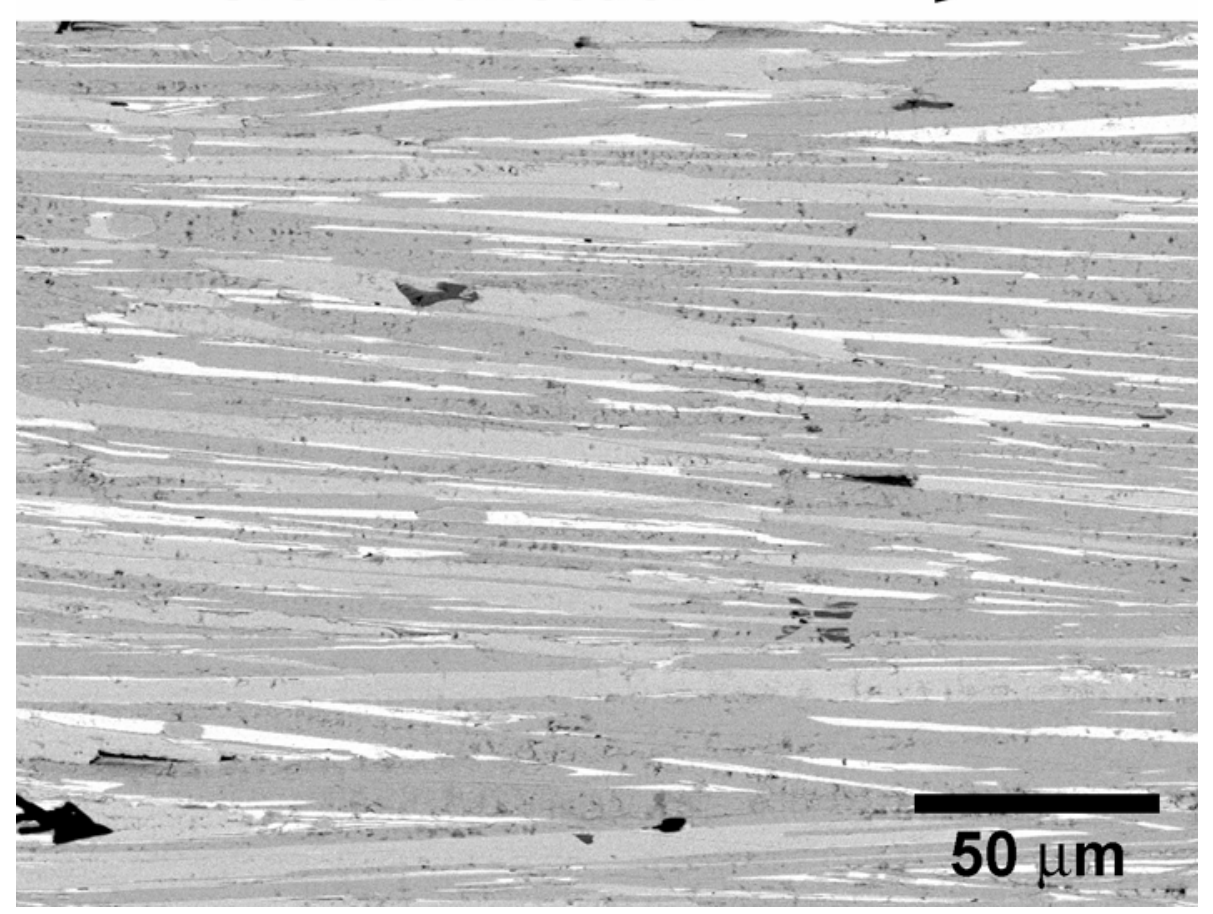


Figure 3

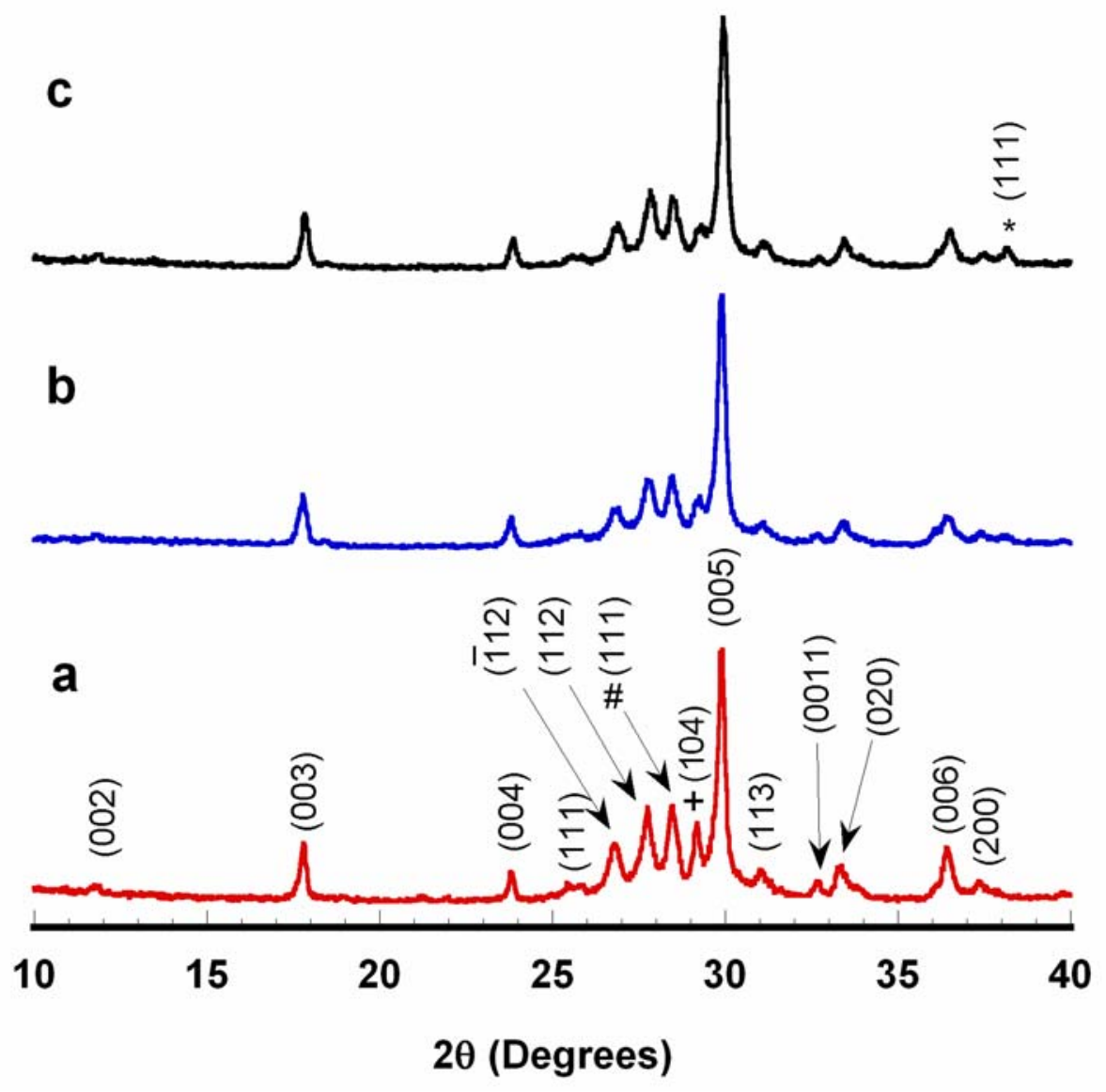


Figure 4

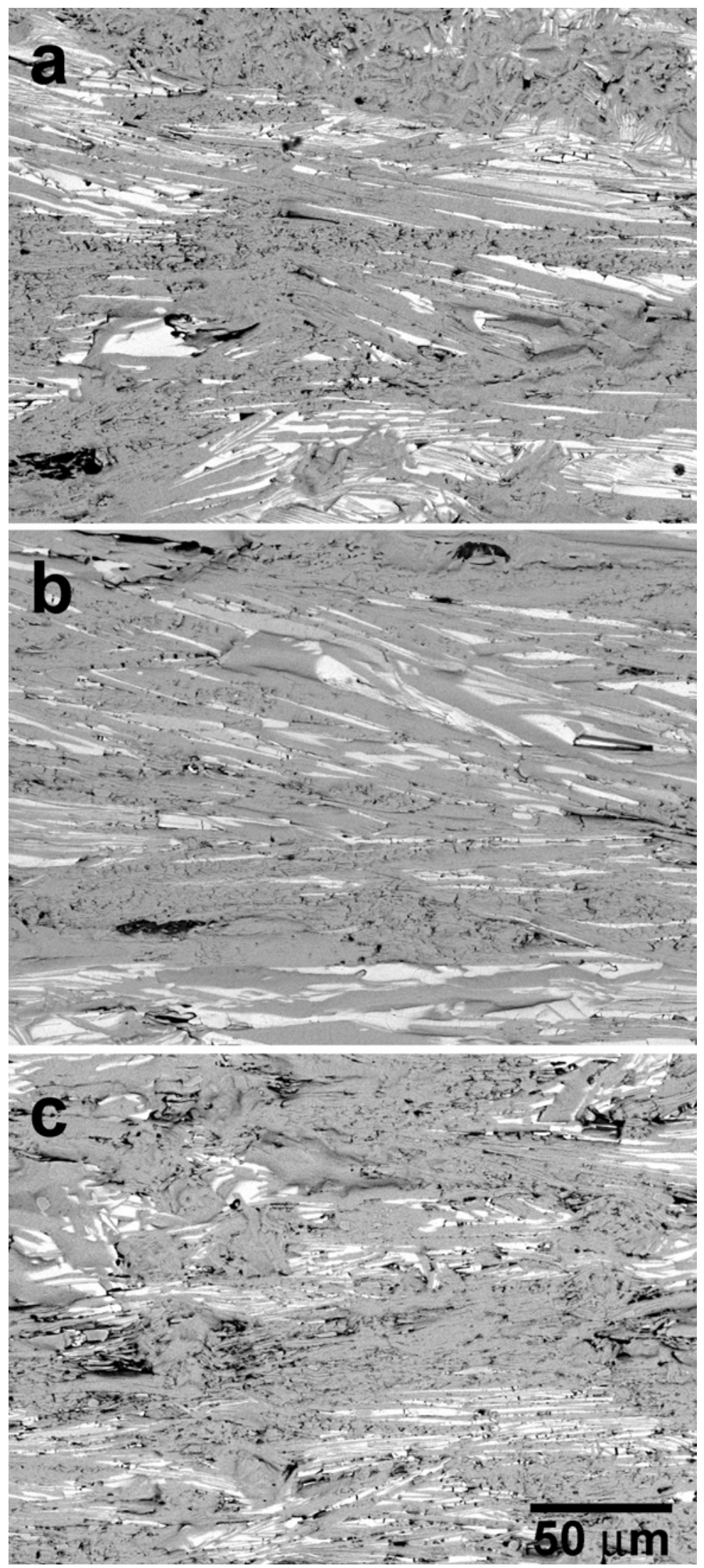


Figure 5

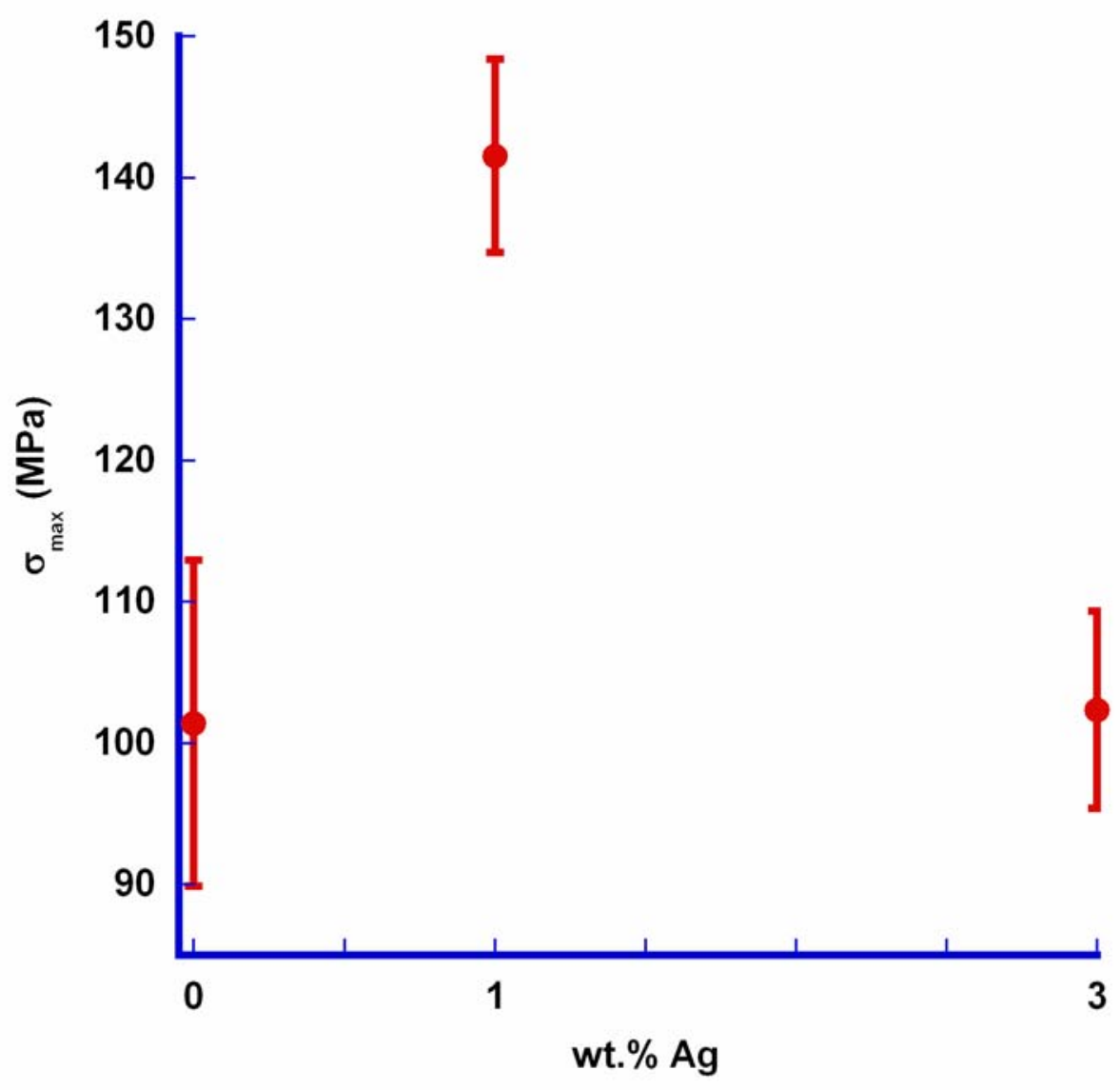


Figure 6

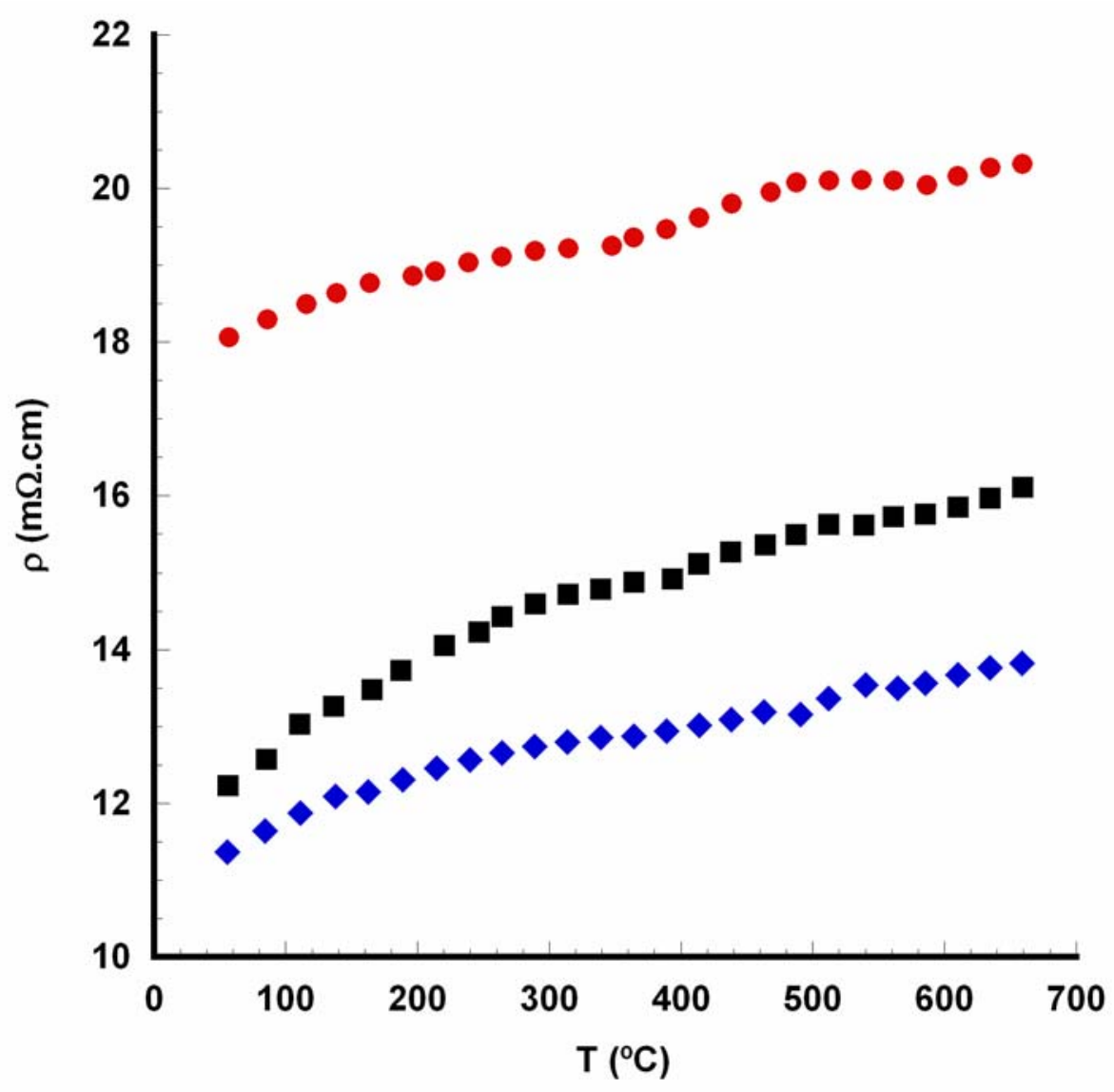


Figure 7

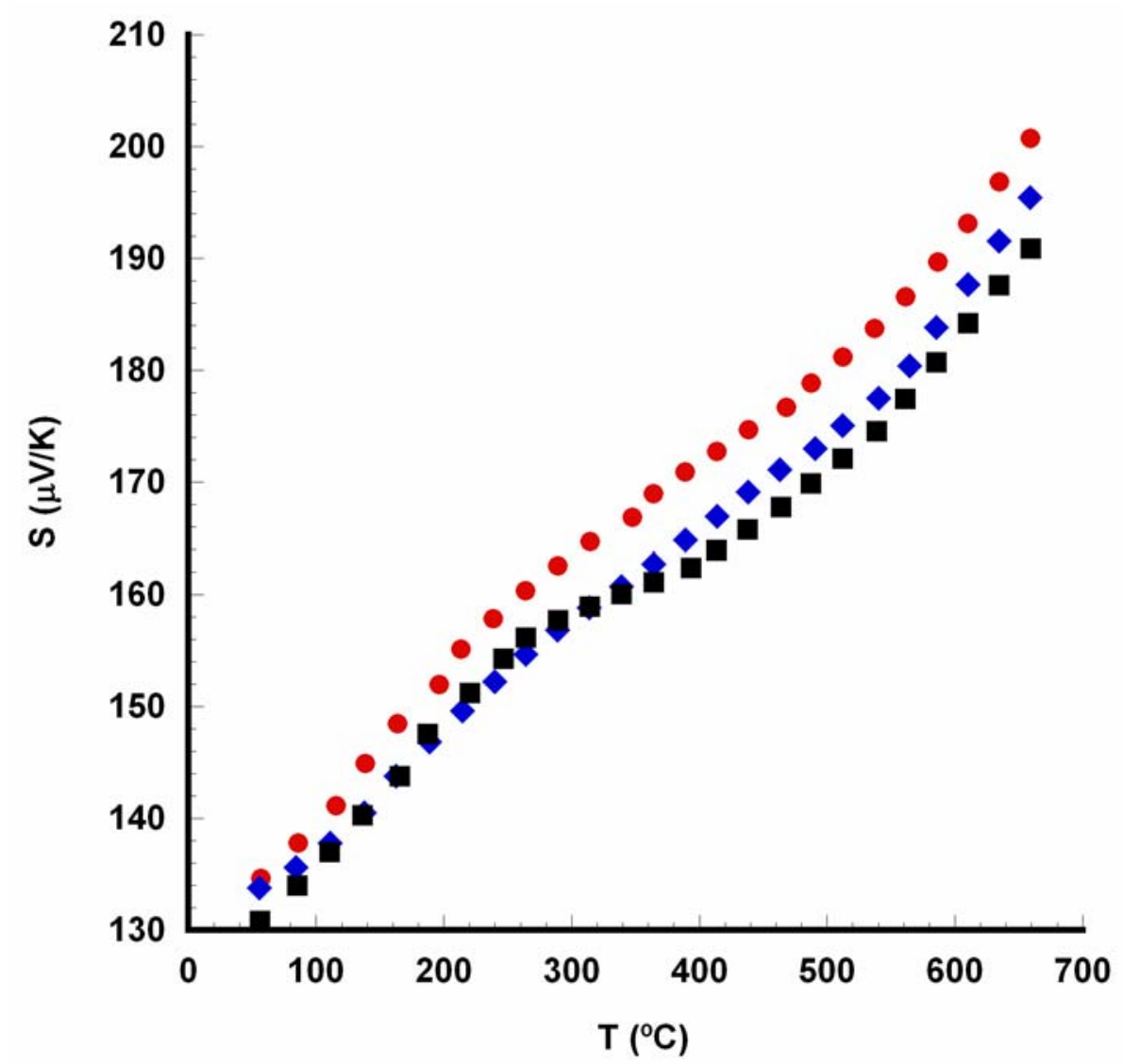


Figure 8

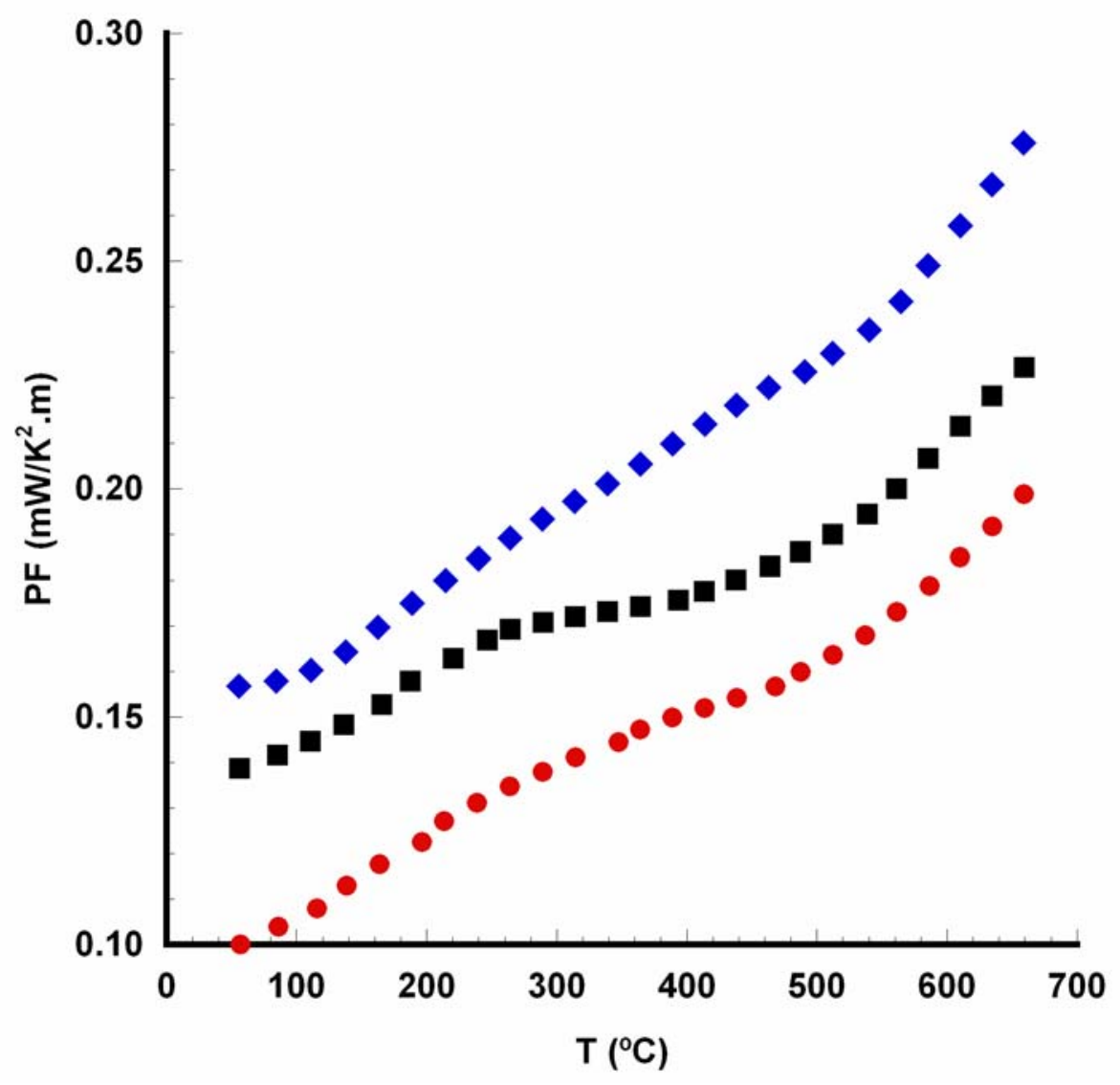

